\title{
Effect of Concrete Age and Creep on the Behavior of Concrete-Filled Steel Tube Columns
}

\author{
HaiYang Wang, ${ }^{1,2}$ XiaoXiong $\mathrm{Zha}^{2}$ and Wei Feng ${ }^{2}$ \\ ${ }^{1}$ School of Environment and Energy, Peking University Shenzhen Graduate School, Shenzhen 518055, China \\ ${ }^{2}$ School of Civil and Environment Engineering, Harbin Institute of Technology Shenzhen Graduate School, Shenzhen 518055, China
}

Correspondence should be addressed to XiaoXiong Zha; zhahero@126.com

Received 4 July 2016; Accepted 19 September 2016

Academic Editor: Doo-Yeol Yoo

Copyright (c) 2016 HaiYang Wang et al. This is an open access article distributed under the Creative Commons Attribution License, which permits unrestricted use, distribution, and reproduction in any medium, provided the original work is properly cited.

The influence of concrete age and creep on the ultimate axial loading capacity of concrete-filled steel tube (CFST) columns is experimentally and numerically investigated. After validation of numerical models, a parametric study is conducted and the results are used to formulate empirical formulas for predicting the ultimate axial load-bearing capacity of the columns. Formulas are also proposed for predicting both the composite creep and aging coefficients of the CFST columns, which consider the confinement action of steel tubes on concrete. Then, the proposed formulas are validated independently by comparing their predictions with existing test results performed by other researchers. The comparisons show that the empirical formulas have the potential to be used in the practical design of CFST columns.

\section{Introduction}

Concrete-filled steel tube (CFST) columns have been extensively used in civil engineering structures over the past few decades. Extensive experimental and theoretical investigations on CFST components have been conducted and are well documented in the literature. The experimental work includes tests reported by O'Shea and Bridge [1] and Giakoumelis and Lam [2], who conducted research on the bearing capacity of short CFST columns. Zhong [3] and Zha [4] also reported their works on short and long CFST columns. Han et al. [5] and Wang [6] also studied property of the CFST under long-time load, while these results cannot be implemented conveniently considering the new code (GB50936-2014). Although significant work has been conducted on the properties of matured CFST columns, less emphasis has been placed on the influence of concrete age. Tan and Qi [7] have worked systematically by testing the effect of creep on columns under axially applied eccentric compressive load. Terry et al. [8] and Luo et al. [9] tested the creep of CFST columns and plain concrete in order to investigate the influence of steel tube reinforcement. Ichinose et al. [10] also reported a series of similar tests to obtain creep coefficients. Naguib and Mirmiran [11] and Liu et al. [12] developed an algorithm for the time-dependent behavior of CFST using the rate of flow method and the double power law functions for the creep of concrete. Shrestha and Chen [13] worked on the aging and creep coefficients of confined concrete, but the effect of steel tube was excluded in their formulas.

This study investigates the effect of concrete age and creep by experimental test and FEM modeling. Then, empirical formulas are proposed by treating a CFST column as a structural component made of a single material through homogenization.

\section{Simulation and Methods}

After pouring concrete into the steel tube, the elastic modulus of concrete increases with age. At the early stage, the steel tube is subjected to higher values of load than that specified by the design code. Thus, the ultimate bearing capacity of the CFST column is lower than the designed value. In this section, laboratory tests and FEM model are used to obtain the time-dependent load-bearing capacity. An empirical formula is established to provide a simple form of calculation for estimating the age-related ultimate load-bearing capacity. 
TABLE 1: Geometrical and mechanical properties of the specimens.

\begin{tabular}{lccccc}
\hline$D(\mathrm{~mm})$ & $T(\mathrm{~mm})$ & $L(\mathrm{~mm})$ & $f_{y}(\mathrm{MPa})$ & $f_{c k}(\mathrm{MPa})$ & $E_{s}(\mathrm{MPa})$ \\
\hline 219 & 4.5 & 766 & 345 & 40.7 & $2.06 e 5$ \\
\hline
\end{tabular}

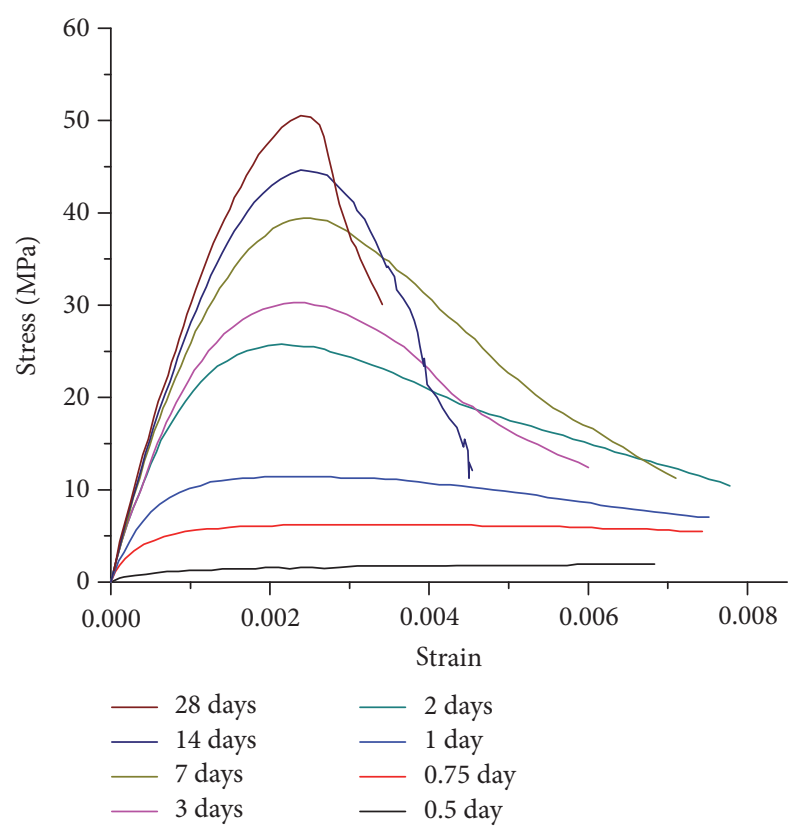

FIGURE 1: Stress strain relations of concrete at different ages.

2.1. FEM Modeling of CFST Columns. The numerical model is implemented in ABAQUS eight-node quadrilateral inplane continuum shell elements which are used for the steel tube whereas the concrete is modeled employing eight-node linear brick element. The bilinear material model is adopted for the steel, with tangent modulus being $5 \%$ of the elastic modulus of $2.06 e 5 \mathrm{MPa}$. The material model used for the concrete is the damaged plasticity model, and hardening of concrete at different ages follows the curves proposed by Yi et al. [14], as shown in Figure 1. Other mechanical and geometrical parameters of the column are given in Table 1. FE meshes of both concrete and steel are shown in Figure 2. The contact between the steel tube and concrete is assumed to be perfect; here the nodes on the interface between solid and shell elements are tied.

Different meshing schemes are tested in order to assess the convergence of the FEM model, and the details are listed in Table 2, where N_Ring, $N$ _Radius, and N_Axial are, respectively, the numbers of elements in the circumferential, radial, and axial directions. E_Section and E_Total are the total number of elements on a cross section and of the whole column, respectively. $N \_3 \mathrm{~d}$ and $N \_28 \mathrm{~d}$ are the ultimate axial loads of the column at ages of 3 days and 28 days.

Figure 3 shows terms of load against relative displacement of the different meshing FE model for concrete at the age 3 of and 28 days. With the increase in the number of elements, from M1 to M6, Table 2 shows the convergence of the ultimate load. When the elements number is more than that of M4, the difference between the different meshing schemes is nonsignificant. Therefore, meshing scheme M4 will be used in the following numerical simulations.

Laboratory tests have been conducted (see Figure 4) on the column specified in Table 1 in order to verify the FEM model. Load-bearing capacity tests are conducted at ages equal to $3,7,14,21,28$, and 49 days.

The experimental test results of the time-dependent elastic modulus at different ages are shown in Table 3, and the load-bearing capacity of the CFST column is shown in Figure 5 as a function of the considered ages. Comparison between experimental and numerical results shows that the FE model can clearly predict the age-dependent load-bearing capacity.

\subsection{Empirical Formula of the Age-Related Load-Bearing Capac-} ity. Parametric studies on a variety of CFST columns presented in Table 4 are conducted to derive an empirical formula for the load-bearing capacity of the CFST columns, whose numerical results are presented in Table 5.

Supposing that the age-strength relationship of concrete in the steel tube has the same form as when it is unconfined, according to ACI-209 [15], the following equation can be established:

$$
\frac{N_{u t}-N_{k}}{N_{u 28}-N_{k}}=\frac{t}{a+b t}
$$

where the two unknown constants in the equation can be estimated by fitting FE results presented in Table 5. Then, $a=1.243$ and $b=0.977$ are obtained with the maximum error of $3.4 \%$. Therefore, the ultimate load-bearing capacity of the CFST column is obtained as follows:

$$
N_{\mathrm{ut}}=N_{k}+\frac{\left(N_{u 28}-N_{k}\right) t}{1.243+0.977 t} .
$$

The previously presented equation is validated through its application on the specimen defined in Table 1, and a comparison between experimental and numerical results is shown in Figure 6. $F(\exp )$ and $F(\mathrm{FEM})$ are obtained applying (2) to the experimental and numerical results, respectively, shown in Figure 5. The predicted ultimate loading capacities obtained from the formula are consistent with those obtained from the experimental tests and FE modeling.

\section{Influence of Creep on CFST Columns}

In this section, a composite creep coefficient of CFST columns is proposed, in order to consider steel confinement, and the factor of the effective aging coefficient is obtained by regression on the FEM results.

3.1. Creep Coefficient of the CFST Column. Yi et al. [14] proposed the age-adjusted effective modulus method, also known as BT theory, which represents an effective method to analyze the long-term effect of concrete creep. An aging coefficient was introduced in order to consider the effect of 


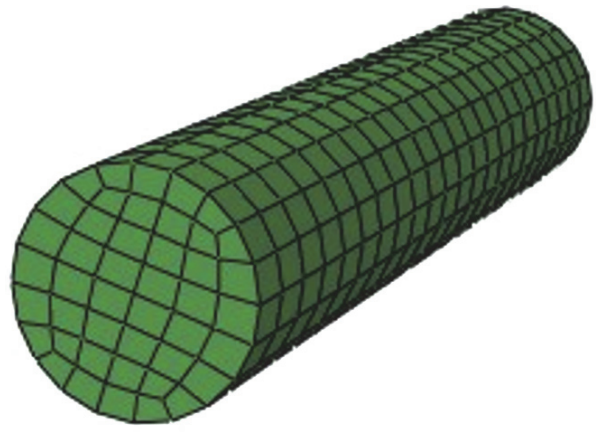

(a)

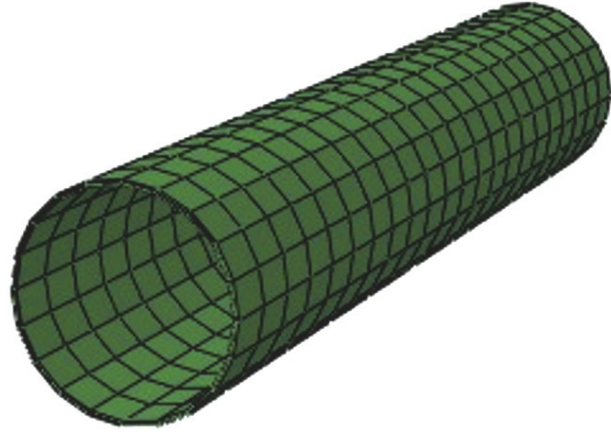

(b)

FIgURE 2: Finite element mesh of (a) concrete and (b) steel tube.

TABLE 2: Meshes parameter and results.

\begin{tabular}{|c|c|c|c|c|c|c|c|}
\hline Model & N_Ring & N_Radius & N_Axial & E_Section & E_Total & N_3 d (kN) & $N \_28 \mathrm{~d}(\mathrm{kN})$ \\
\hline M1 & 12 & 2,3 & 18 & 56 & 1120 & 2240 & 2868 \\
\hline M2 & 12 & 3,4 & 18 & 68 & 1224 & 2256 & 2904 \\
\hline M3 & 16 & 3,4 & 18 & 96 & 1728 & 2285 & 2942 \\
\hline M4 & 20 & 3,4 & 18 & 104 & 1872 & 2358 & 2965 \\
\hline M5 & 24 & 3,4 & 18 & 132 & 2376 & 2372 & 2972 \\
\hline M6 & 28 & 3,4 & 18 & 160 & 2880 & 2377 & 2979 \\
\hline
\end{tabular}

concrete aging on the ultimate creep, and the integral equation for creep was transformed into an algebraic equation by employing the integral mean value theorem.

When stress varies with time, the corresponding total strain at time $t$ can be expressed as follows:

$$
\begin{aligned}
\varepsilon_{c}^{c}(t)= & \frac{\sigma_{c 1}^{0}\left(\tau_{0}\right)}{E_{c}\left(\tau_{0}\right)}\left[1+\varphi\left(t, \tau_{0}\right)\right] \\
& +\frac{1}{E_{c}\left(\tau_{0}\right)} \int_{\tau_{0}}^{t} \frac{d \sigma_{c 1}(\tau)}{d \tau}[1+\varphi(t, \tau)] d \tau,
\end{aligned}
$$

where $\varepsilon_{c}^{c}(t)$ is the strain of concrete when creep is with no steel confinement at age $t$ days, $\sigma_{c 1}^{0}\left(\tau_{0}\right)$ is the stress of the concrete at $\tau_{0}$ days, $E_{c}\left(\tau_{0}\right)$ is the elastic modulus of concrete at $\tau_{0}$ days, and $\varphi\left(t, \tau_{0}\right)$ is the creep coefficient at $t$ when loaded at $\tau_{0}$ days.

Applying the integral mean value theorem on formula (3) leads to

$$
\varepsilon_{c}^{c}(t)=\frac{\sigma_{c 1}^{0}\left(\tau_{0}\right)}{E_{c}\left(\tau_{0}\right)}\left[1+\varphi\left(t, \tau_{0}\right)\right]+\frac{\sigma_{c 1}(t)-\sigma_{c 1}^{0}\left(\tau_{0}\right)}{E_{\varphi}} .
$$

Consider

$$
E_{\varphi}=\frac{E_{c}\left(\tau_{0}\right)}{1+\rho \varphi\left(t, \tau_{0}\right)},
$$

where $\sigma_{c 1}(t)$ is the stress of concrete at age of $t$ days. $E_{\varphi}$ is the age-adjusted effective modulus. $\rho$ is the aging coefficient of concrete that is calculated as follows:

$$
\rho=\frac{E_{c}\left(\tau_{0}\right)}{1-e^{-\varphi\left(t, \tau_{0}\right)}}-\frac{1}{\varphi\left(t, \tau_{0}\right)} .
$$

The following calculation is based on the assumption of plane section and superposition principle of creep regardless of the toroidal shrinkage and strain. The axial strains of concrete and steel tube at age of $\tau_{0}$ are denoted as $\varepsilon_{c 1}^{0}$ and $\varepsilon_{s 1}^{0}$, respectively, whereas $\sigma_{c 1}^{0}$ and $\sigma_{s 1}^{0}$ represent the related stresses. The creep of concrete with no steel confinement is $\varepsilon_{c}^{c}=\varepsilon_{c}^{0} \varphi\left(t, \tau_{0}\right)$ at the age of $t$. As a result of the effect of the steel tube confinement, the concrete creep is reduced to $\varepsilon_{c 1}^{c}$, as shown in Figure 7.

It is clear that the strain increment of the steel tube is the actual concrete creep. Hence,

$$
\begin{aligned}
\varepsilon_{s c 1}^{c} & =\varepsilon_{s 1}^{c}, \\
\varepsilon_{s 1}^{c} & =\varepsilon_{c}^{c}-\varepsilon_{c 1}^{c}, \\
\varepsilon_{s 1}^{0} & =\varepsilon_{c 1}^{0},
\end{aligned}
$$

where $\varepsilon_{s c 1}^{c}$ is the axial creep strain of the CFST column, $\varepsilon_{s 1}^{c}$ is the axial strain of steel tube due to concrete creep, $\varepsilon_{c}^{c}$ is the creep strain of the concrete with no steel confinement, $\varepsilon_{c 1}^{c}$ is the reduced strain of the concrete considering the steel tube confinement, $\varepsilon_{s 1}^{0}$ is the strain of the steel tube when loaded at $\tau_{0}$ days, and $\varepsilon_{c 1}^{0}$ is the strain of the concrete when loaded at $\tau_{0}$ days.

The total strain of CFST, or concrete in the steel tube, is derived as follows:

$$
\varepsilon(t)=\varepsilon_{c 1}^{0}+\varepsilon_{c}^{c}-\varepsilon_{c 1}^{c}
$$




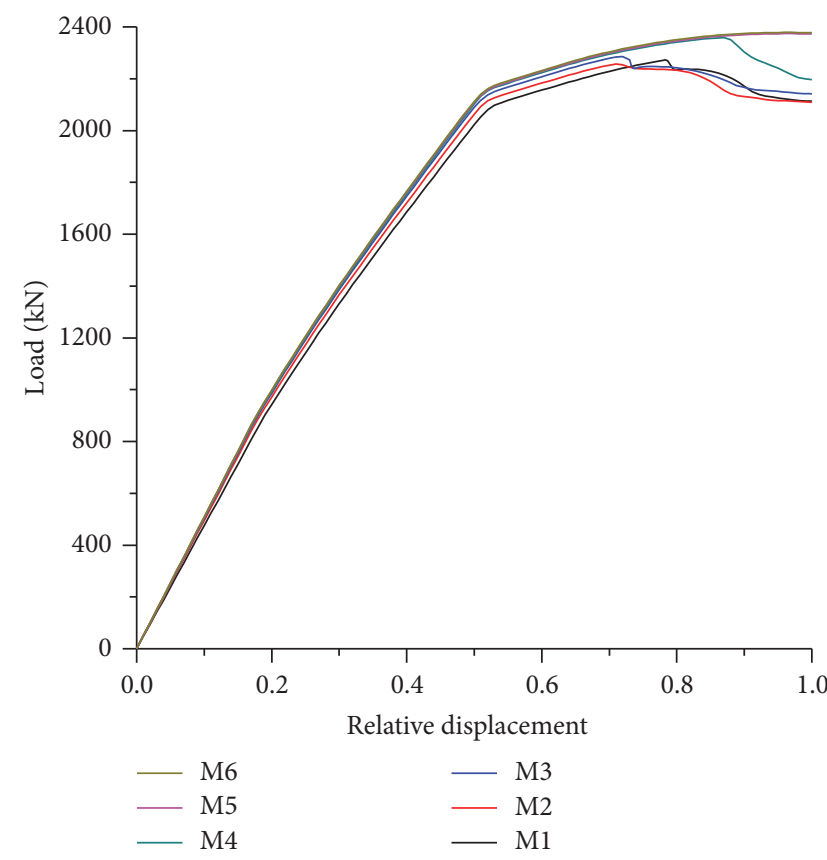

(a)

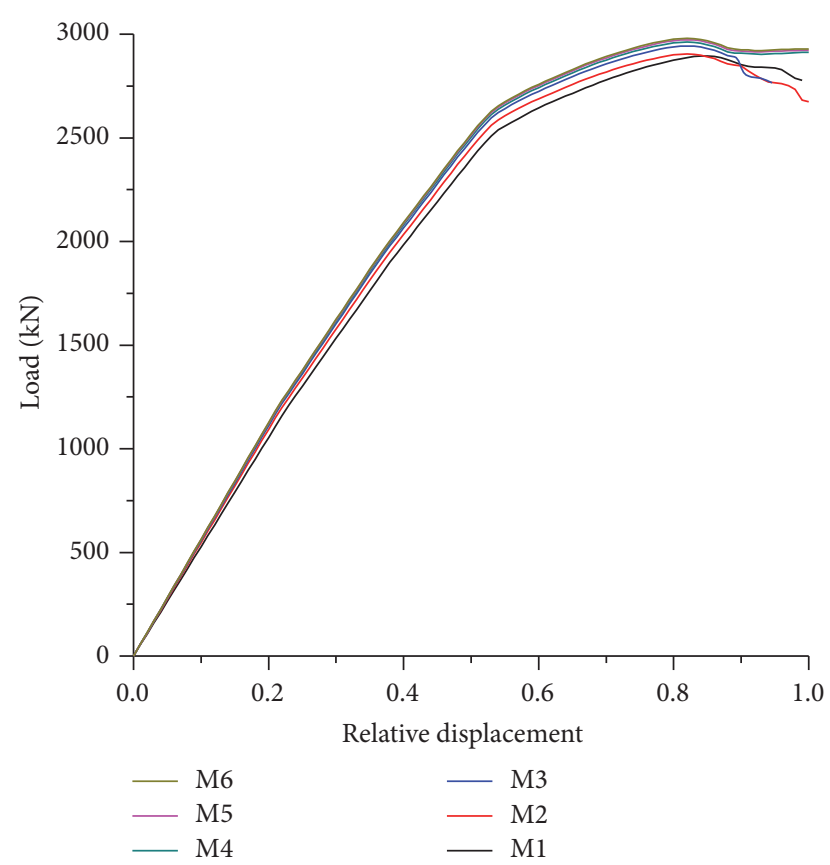

(b)

FIgURE 3: The load curve for different meshes at the (a) age of 3 days and (b) age of 28 days.

From (3), it becomes

$$
\begin{aligned}
\varepsilon(t)= & \frac{\sigma_{c 1}^{0}}{E_{c}\left(\tau_{0}\right)}\left[1+\varphi\left(t, \tau_{0}\right)\right] \\
& +\frac{1}{E_{c}\left(\tau_{0}\right)} \int_{\tau_{0}}^{t} \frac{d \sigma_{c 1}(\tau)}{d \tau}[1+\varphi(t, \tau)] d \tau, \\
\varepsilon_{c 1}^{0}= & \frac{\sigma_{c 1}^{0}}{E_{c}\left(\tau_{0}\right)}, \\
\varepsilon_{c}^{c}= & \frac{\sigma_{c 1}^{0}}{E_{c}\left(\tau_{0}\right)} \varphi\left(t, \tau_{0}\right) .
\end{aligned}
$$

From (8) and (9), it is obtained that

$$
\varepsilon_{c 1}^{c}=-\frac{1}{E_{c}\left(\tau_{0}\right)} \int_{\tau_{0}}^{t} \frac{d \sigma_{c 1}(\tau)}{d \tau}[1+\varphi(t, \tau)] d \tau
$$

and by considering (4) and (5)

$$
\begin{aligned}
\varepsilon_{c 1}^{c} & =-\frac{\left[1+\rho \varphi\left(t, \tau_{0}\right)\right]\left[\sigma_{c 1}(t)-\sigma_{c 1}^{0}\right]}{E_{c}\left(\tau_{0}\right)} \\
& =-\frac{\left[1+\rho \varphi\left(t, \tau_{0}\right)\right] \sigma_{c 1}^{c}}{E_{c}\left(\tau_{0}\right)}
\end{aligned}
$$

where $\sigma_{c 1}^{c}$ is the stress change of the concrete due to creep. In spite of extensive microcracks that will be induced in the core as reported by previous researchers and splitting cracks that can occur at $30 \%$ to $40 \%$ stress [16-18], the cracks could close if they are subject to an outer sustained compression

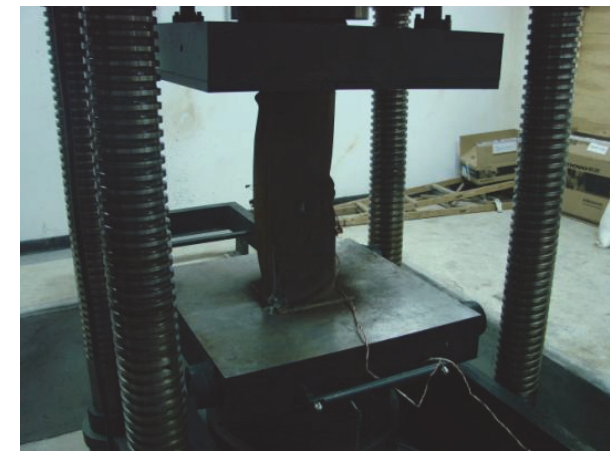

FIGURE 4: Load-bearing capacity test of the CFST column.

TABLE 3: Elastic modulus of the concrete at different age.

\begin{tabular}{lccccc}
\hline Age (days) & 3 & 7 & 14 & 21 & 28 \\
\hline$E_{c}(\mathrm{MPa})$ & 30680 & 32319 & 34053 & 35101 & 35905 \\
\hline
\end{tabular}

load at an early age. The confining stress would delay the formation of splitting cracks and restrict the widening of splitting cracks $[19,20]$, and the confinement effect appears based on the splitting cracks formation [21]. There will be no or little splitting cracks in the core concrete under the maximum sustained load after seven stages at an early age that is $40 \%$ bearing capacity of the specimens in the experiment and this had been contained naturally in the total creep. Therefore, the effect of splitting cracks on the creep was not considered separately here. 
TABLE 4: Axially compressed short columns.

\begin{tabular}{lccccc}
\hline Number & $D \times T \times L(\mathrm{~mm})$ & $f_{y}(\mathrm{MPa})$ & $f_{c k}(\mathrm{MPa})$ & $\alpha$ & $\xi$ \\
\hline 1 & $1000 \times 12 \times 3000$ & 345 & 40.7 & 0.050 & 0.422 \\
2 & $1000 \times 18 \times 3000$ & 345 & 40.7 & 0.076 & 0.645 \\
3 & $1000 \times 24 \times 3000$ & 345 & 40.7 & 0.103 & 0.876 \\
4 & $1000 \times 30 \times 3000$ & 345 & 40.7 & 0.132 & 1.117 \\
5 & $1000 \times 36 \times 3000$ & 345 & 40.7 & 0.161 & 1.366 \\
\hline
\end{tabular}

The equilibrium force condition in the axial direction satisfies the following equations:

$$
\begin{aligned}
\sigma_{c 1}^{c} A_{c}+\sigma_{s 1}^{c} A_{s} & =0, \\
\sigma_{c 1}^{c} & =-\frac{A_{s} \sigma_{s 1}^{c}}{A_{c}}=-\alpha \sigma_{s 1}^{c},
\end{aligned}
$$

where $\sigma_{s 1}^{c}$ is the stress change of steel tube due to creep.

Not considering the creep of the steel tube and taking steel as elastic modulus value a constant give

$$
\varepsilon_{s 1}^{c}=\frac{\sigma_{s 1}^{c}}{E_{s}}=-\frac{\sigma_{c 1}^{c}}{\alpha E_{s}}
$$

and (11) becomes

$$
\frac{\sigma_{c 1}^{0}}{E_{c}\left(\tau_{0}\right)} \varphi\left(t, \tau_{0}\right)+\frac{\left[1+\rho \varphi\left(t, \tau_{0}\right)\right] \sigma_{c 1}^{c}}{E_{c}\left(\tau_{0}\right)}=-\frac{\sigma_{c 1}^{c}}{\alpha E_{s}} ;
$$

letting $n=E_{s} / E_{c}\left(\tau_{0}\right)$ in (14), the change in stresses on concrete and steel tube because of the concrete creep is expressed as follows:

$$
\begin{aligned}
\sigma_{c 1}^{c} & =-\frac{\alpha n \sigma_{c 1}^{0} \varphi\left(t, \tau_{0}\right)}{1+\alpha n\left[1+\rho\left(t, \tau_{0}\right) \varphi\left(t, \tau_{0}\right)\right]} \\
\sigma_{s 1}^{c} & =\frac{n \sigma_{c 1}^{0} \varphi\left(t, \tau_{0}\right)}{1+\alpha n\left[1+\rho\left(t, \tau_{0}\right) \varphi\left(t, \tau_{0}\right)\right]}
\end{aligned}
$$

Consider the following equations:

$$
\begin{aligned}
& \sigma_{s 1}^{c}=\varepsilon_{s 1}^{c} E_{s}=\varepsilon_{s c 1}^{c} E_{s}, \\
& \sigma_{c 1}^{0}=E_{c}\left(\tau_{0}\right) \varepsilon_{s c 1}^{0}=\frac{E_{s} \varepsilon_{s c 1}^{0}}{n} .
\end{aligned}
$$

Equations (16) are introduced into (15a) and (15b) to obtain the total creep strain $\varepsilon_{s c 1}^{c}$ of the CFST column, as follows:

$$
\varepsilon_{s c 1}^{c}=\frac{\varepsilon_{s c 1}^{0} \varphi\left(t, \tau_{0}\right)}{1+\alpha n\left[1+\rho\left(t, \tau_{0}\right) \varphi\left(t, \tau_{0}\right)\right]} .
$$

Here the creep prediction function $\varphi\left(t, \tau_{0}\right)$ employed the equation from ACI-209 [15]. Then, the composite creep

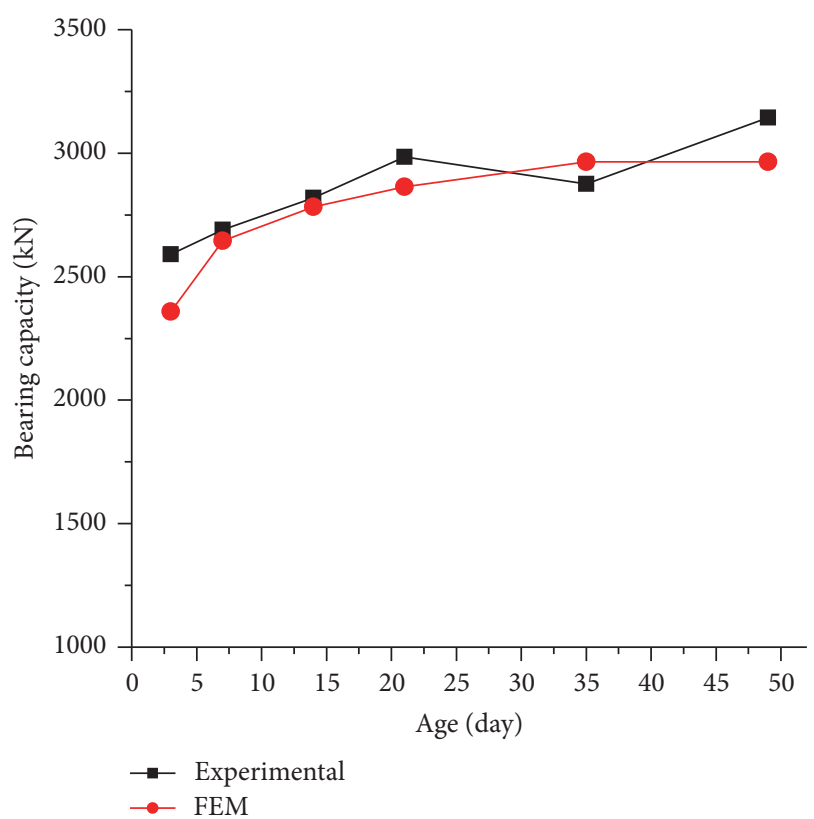

FIGURE 5: Load-bearing capacity of the CFST column at different ages.

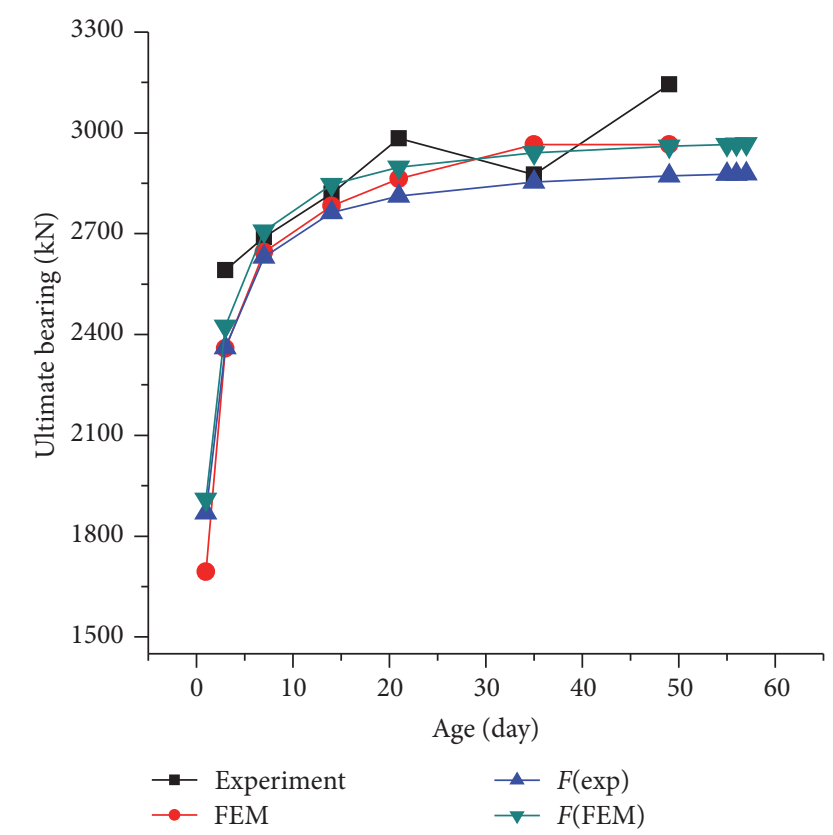

FIGURE 6: Comparison with the experimental and numerical results.

coefficient of the CFST, $\varphi_{s c}\left(t, \tau_{0}\right)=\varepsilon_{s c 1}^{c} / \varepsilon_{s c}^{0}$, is obtained as follows:

$$
\begin{aligned}
\varphi_{s c}\left(t, \tau_{0}\right) & =\frac{\varphi\left(t, \tau_{0}\right)}{1+\alpha n\left[1+\rho_{s c}\left(t, \tau_{0}\right) \varphi\left(t, \tau_{0}\right)\right]}, \\
\varphi\left(t, \tau_{0}\right) & =\frac{\left(t-\tau_{0}\right)^{0.6}}{10+\left(t-\tau_{0}\right)^{0.6}} \varphi_{\mathrm{cu}}, \\
\varphi_{\mathrm{cu}} & =2.35 \gamma_{\mathrm{la}} \gamma_{h} \gamma_{\psi} \gamma_{s} \gamma_{\lambda} \gamma_{a},
\end{aligned}
$$


TABLE 5: Ultimate load-bearing capacity of the axially compressed columns.

\begin{tabular}{lcccccccccc}
\hline & $N_{k}(\mathrm{kN})$ & \multicolumn{3}{c}{$N_{\mathrm{ut}}\left(\times 10^{3} \mathrm{kN}\right)$} & \multicolumn{3}{c}{$\left(N_{\mathrm{ut}}-N_{k}\right) /\left(N_{\mathrm{u} 28}-N_{k}\right)$} \\
Concrete age (day) & 0 & 1 & 3 & 7 & 14 & 28 & 1 & 3 \\
\hline Number 1 & 13.070 & 30.876 & 43.497 & 49.731 & 52.161 & 54.934 & 0.425 & 0.727 & 0.876 & 0.934 \\
Number 2 & 19.235 & 38.841 & 51.250 & 57.432 & 59.979 & 63.839 & 0.440 & 0.718 & 0.856 & 0.913 \\
Number 3 & 25.238 & 45.828 & 58.000 & 64.098 & 66.483 & 70.591 & 0.454 & 0.722 & 0.857 & 0.909 \\
Number 4 & 31.084 & 52.171 & 64.129 & 70.131 & 72.343 & 76.533 & 0.464 & 0.727 & 0.859 & 0.908 \\
Number 5 & 36.770 & 58.070 & 69.795 & 75.706 & 77.777 & 81.960 & 0.471 & 0.731 & 0.862 & 0.907 \\
\hline
\end{tabular}

$N_{k}=A_{s} f_{y} ; N_{u 28}$ is the load-bearing capacity when the concrete age is equal to 28 days.

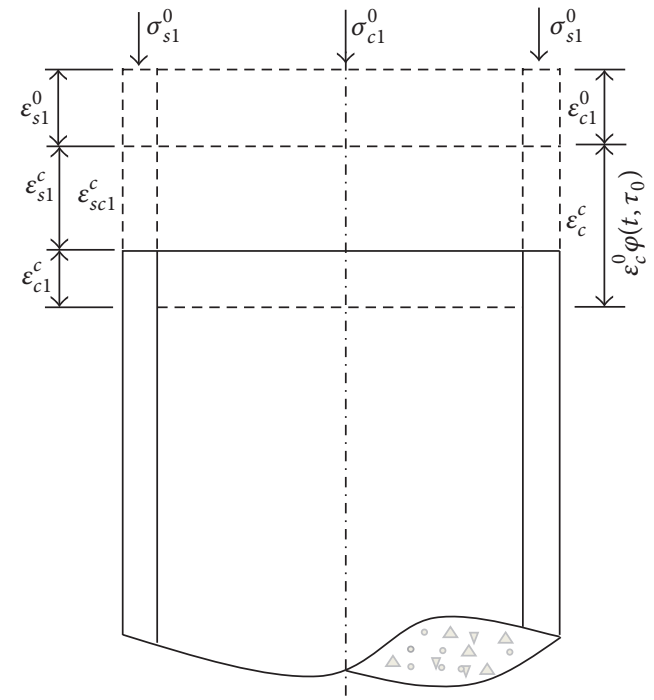

FIGURE 7: Creep strain of CFST member under axial compression.

where $\varphi_{\mathrm{cu}}$ is the ultimate creep of concrete; $\gamma_{\mathrm{la}}$ is the influence coefficient of loading age; $\gamma_{h}$ is influence coefficient of average thickness or the ratio of volume and area of the component; $\gamma_{\psi}$ is influence coefficient of the fine aggregate content; $\gamma_{s}$ is influence coefficient of the concrete slump; $\gamma_{\lambda}$ is influence coefficient of the ambient humidity; $\gamma_{a}$ is influence coefficient of the air content.

In this study, $\rho_{s c}\left(t, \tau_{0}\right)$ represents the aging coefficient that introduce the effect of not only concrete age but also the steel tube confinement when the CFST column is considered as a single homogeneous material, which is distinguished by $\rho\left(t, \tau_{0}\right)$, the aging coefficient of concrete.

Experimental test and FEM creep analysis of the CFST column are conducted in order to determine the aging coefficient, $\rho_{s c}\left(t, \tau_{0}\right)$.

3.2. Experimental Test and FEM Simulation of the Creep Model during Construction. A special loading device was designed and manufactured in order to simulate the loading process during construction, as shown in Figure 8. Six columns, divided into two groups, were tested. The three columns in the first group are filled with concrete with recycled aggregates, whereas the other three columns in the second group are filled with concrete with conventional aggregates. The volume percentage of the expansive agent is $0 \%, 5 \%$, and $10 \%$ for the

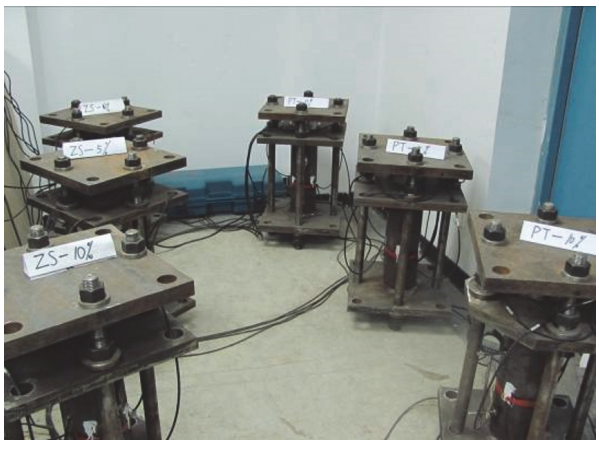

Figure 8: Experimental testing devices.

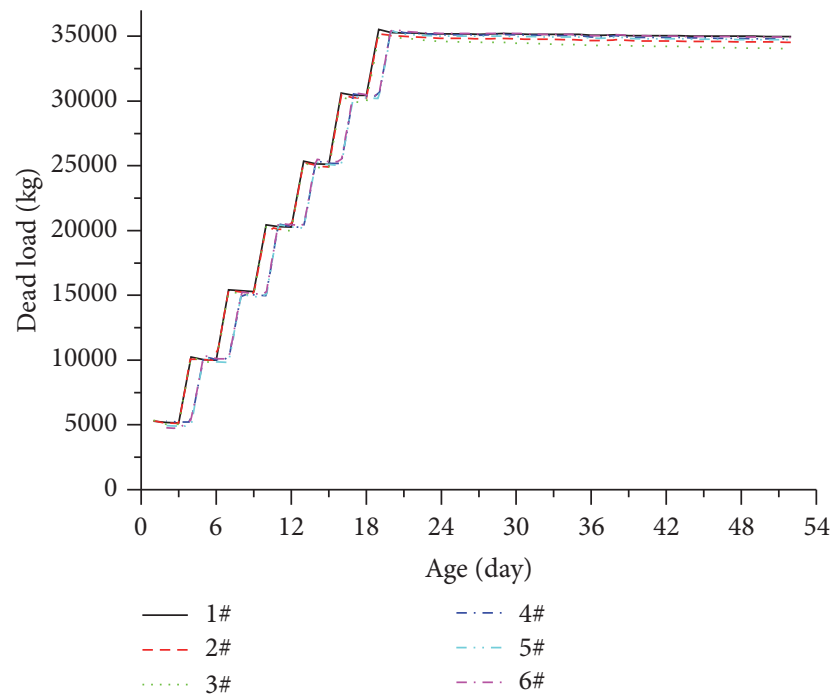

FIGURE 9: The dead load applied at related time.

three columns in each group, respectively. The design details of the columns are shown in Table 6.

The ultimate bearing capacity of the columns is designed as $1,100 \mathrm{kN}$, whose $40 \%$ represents the maximum dead load of $350 \mathrm{kN}$ reached at the final stage of loading. The entire loading process is divided into seven stages and the load at each stage is recorded by the force sensor, as shown in Table 7 and Figure 9 . An initial load of approximately $50 \mathrm{kN}$ is applied to all columns of the two groups when concrete is three days 
TABLE 6: Geometrical and mechanical properties of tests columns.

\begin{tabular}{lccccccc}
\hline Number & $D(\mathrm{~mm})$ & $T(\mathrm{~mm})$ & $H(\mathrm{~mm})$ & $f_{y}(\mathrm{MPa})$ & $f_{c k}(\mathrm{MPa})$ & Aggregate kind & Percent of expansive \\
\hline $1 \#$ & 133 & 4.5 & 400 & 345 & 30.4 & Recycled & 0 \\
2\# & 133 & 4.5 & 400 & 345 & 30.4 & Recycled & 5 \\
$3 \#$ & 133 & 4.5 & 400 & 345 & 30.4 & Recycled & 10 \\
$4 \#$ & 133 & 4.5 & 400 & 345 & 30.4 & Conventional & 0 \\
$5 \#$ & 133 & 4.5 & 400 & 345 & 30.4 & Conventional & 5 \\
$6 \#$ & 133 & 4.5 & 400 & 345 & 30.4 & Conventional & 10 \\
\hline
\end{tabular}

TABLE 7: Registered load at each stage (kN).

\begin{tabular}{|c|c|c|c|c|c|c|c|}
\hline Number & 1st stage & 2nd stage & 3rd stage & 4th stage & 5th stage & 6th stage & 7th stage \\
\hline $1 \#$ & 53.05 & 102.45 & 154.42 & 204.31 & 253.60 & 306.10 & 355.20 \\
\hline $2 \#$ & 53.31 & 103.40 & 153.87 & 203.30 & 252.75 & 305.05 & 354.28 \\
\hline $3 \#$ & 53.54 & 102.70 & 152.94 & 202.90 & 252.58 & 303.37 & 349.58 \\
\hline $4 \#$ & 54.48 & 103.40 & 151.44 & 208.40 & 253.92 & 305.79 & 355.70 \\
\hline $5 \#$ & 52.90 & 103.16 & 150.71 & 204.46 & 253.00 & 304.43 & 354.28 \\
\hline $6 \#$ & 49.40 & 103.50 & 152.39 & 205.95 & 255.11 & 306.54 & 355.99 \\
\hline
\end{tabular}

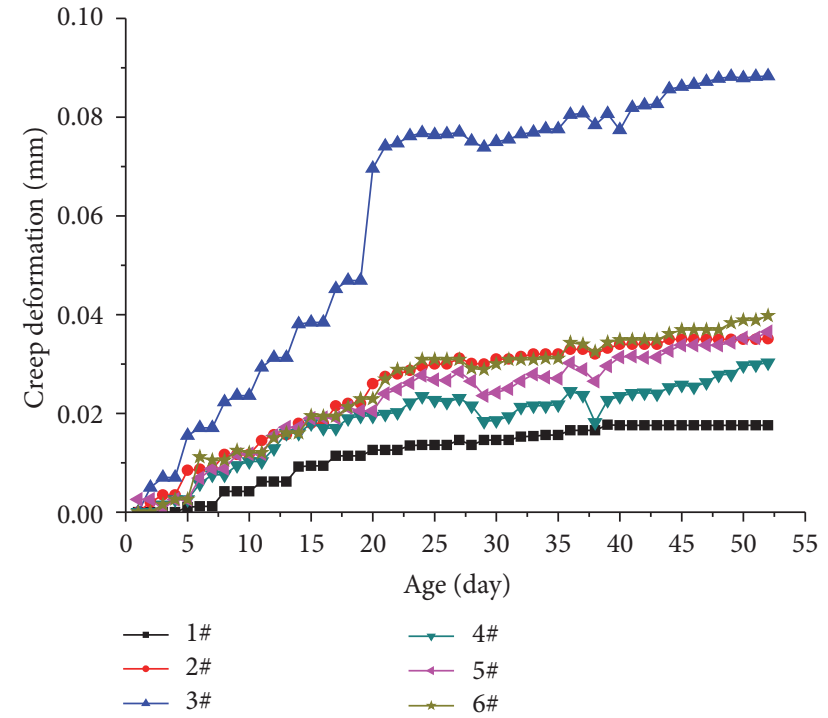

FIGURE 10: Longitudinal creep deformation curve obtained by FE model.

old. Dead load increases by approximately $50 \mathrm{kN}$ at each stage with a three-day interval, until it reaches $350 \mathrm{kN}$.

The creep deformation of the columns is measured by excluding the instantaneous displacements from the total displacement, as shown in Figure 10. Instantaneous displacements from the dead load are recorded immediately after such a load is applied, at each stage of the loading process. From Figure 10, the longitudinal deformation of the columns caused by the creep is notable and an increase in the expansion agent results in a larger creep deformation.

Column 4 is modeled by ABAQUS using a user-supplied subroutine of the creep effect. The creep model of ACI-209 [15], which considers the moist-cured condition, is adopted in the subroutine, where the progression method proposed

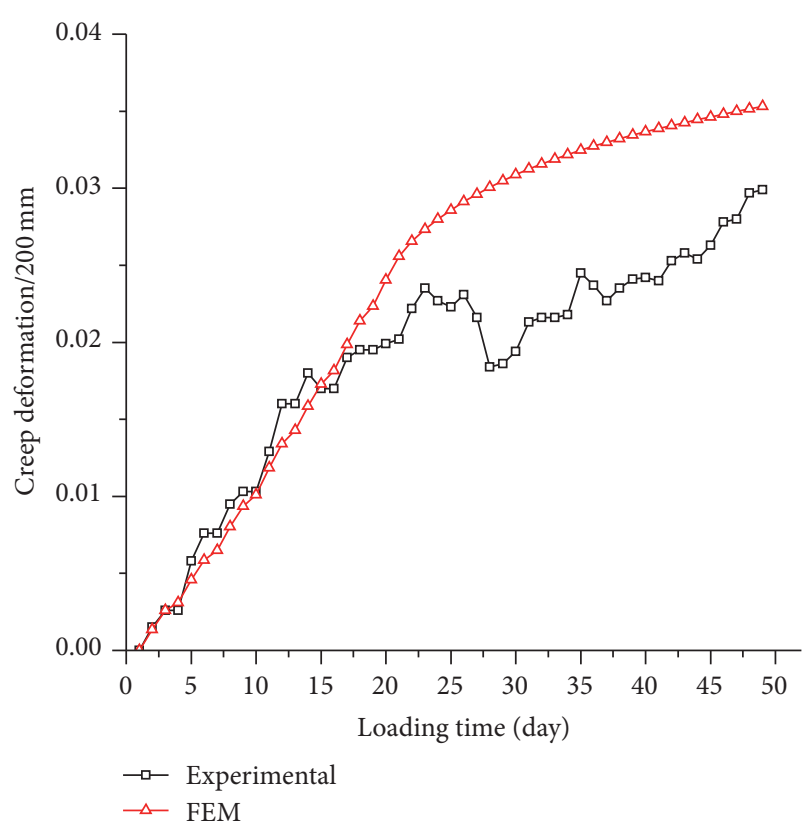

FIGURE 11: Experimental and numerical longitudinal creep deformation curves of specimen $4 \#$.

by Gao et al. [22] is used to consider the change in concrete elastic modulus with age.

Creep deformation of column 4 obtained from the FE analysis is compared with the experimental results shown in Figure 11. In general, the FE solutions are consistent with the experimental test results.

After validating the FE analysis, the model is used to evaluate the aging coefficient $\rho_{s c}\left(t, \tau_{0}\right)$ of the columns specified in Table 8 ; here the composite creep coefficient $\varphi_{s c}\left(t, \tau_{0}\right)$ is obtained by ratio between creep and instantaneous displacements from the numerical result, shown in Figure 12. 
TABLE 8: Parameters of column needed in calculation.

\begin{tabular}{lccccccc}
\hline$D(\mathrm{~mm})$ & $T(\mathrm{~mm})$ & $H(\mathrm{~mm})$ & $f_{y}(\mathrm{MPa})$ & $f_{c k}(\mathrm{MPa})$ & $\tau_{0}($ day $)$ & TL $($ day $)$ & $\varphi_{\text {cu }}$ \\
\hline 1000 & $12 \sim 36$ & 4000 & 345 & 40.7 & 7 & 50 & 2.12 \\
\hline
\end{tabular}

TL is the time of the load duration; $\varphi_{\mathrm{cu}}$ is the ultimate creep coefficient of concrete according to Terry et al. [8].

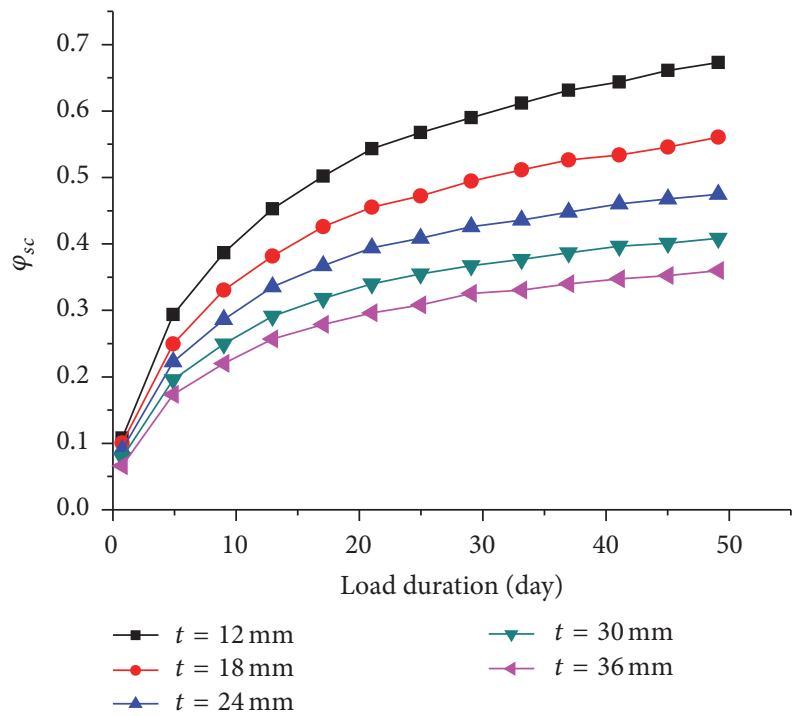

FIgURE 12: Composite creep coefficient.

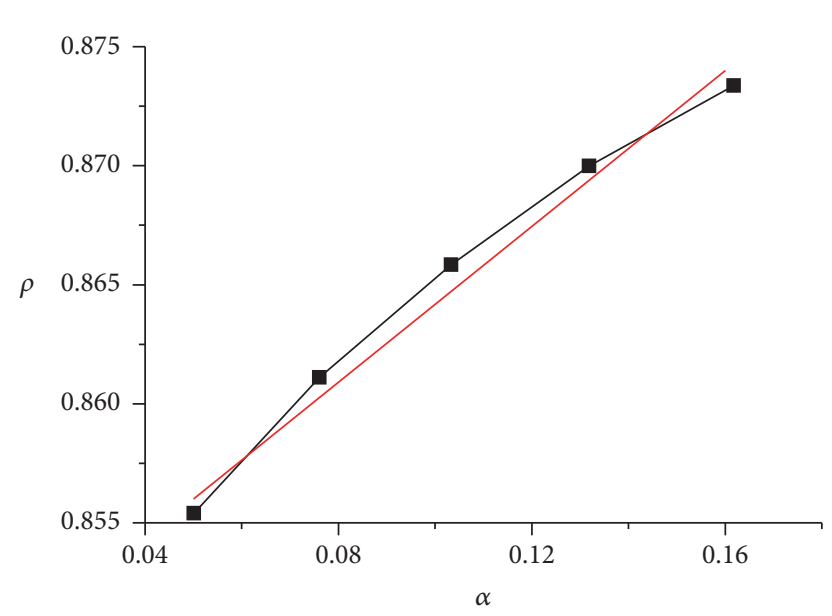

FIgURE 13: Aging coefficient of CFST column.

$\rho_{s c}\left(t, \tau_{0}\right)$ can be back calculated employing (18a), (18b), and $(18 \mathrm{c})$ with known $\varphi_{s c}\left(t, \tau_{0}\right)$ in Figure 12. Figure 13 shows the resulting aging coefficients, which are almost linear for the steel ratio $\alpha$ ranging from 0.05 to 0.20 , representing the typical reinforcement ratio of practical designs. Thus, the aging coefficient within this range can be approximately computed as follows:

$$
\rho_{s c}\left(t, \tau_{0}\right)=0.848+0.16 \alpha
$$

Then, the composite creep coefficient $\varphi_{s c}\left(t, \tau_{0}\right)$ of a CFST column can be calculated employing (18a), (18b), (18c), and (19).

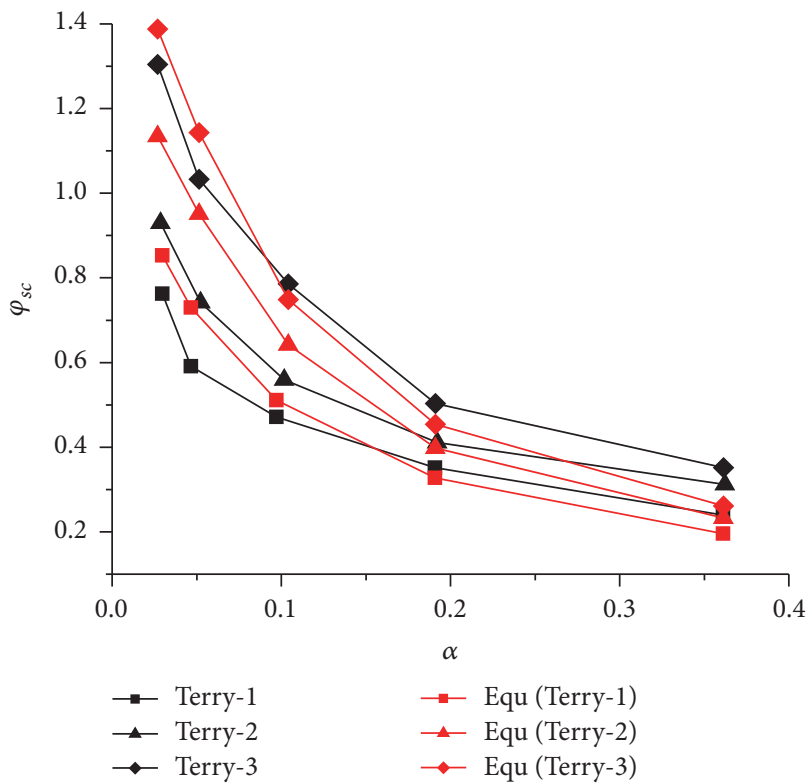

FIgURE 14: Composite creep coefficient compared with results of Terry et al. [8].

Predictions by (18a), (18b), and (18c) are compared with the test results from the studies of Terry et al. [8], in order to verify such equations, as shown in Figure 14, where $\mathrm{Equ}$ (Terry-1) is the equation result obtained by (18a), (18b), and (18c) related to the experimental test of Terry-1. A quite agreement can be seen, with some differences due to the different value adoptions of the ultimate creep of concrete and the loading duration.

\section{Conclusion}

In this study, the effect of concrete age and creep on the ultimate loading capacity of CFST columns had been experimentally and numerically investigated. The validated numerical models were employed in order to propose a set of empirical equations that can be used to predict the axial loading capacity of CFST columns with different concrete ages and composite creep coefficients.

According to the analysis of formula derivation and verification by experimental test and FE method, the ultimate bearing capacity considering the age of the CFST column can be calculated using (2). When treating the CFST column as a single material, both the unity creep and the aging coefficient, determined by employing (18a), (18b), (18c), and (19), respectively, can be used for long-term property analysis. 
Equations in this study will be simplified to a certain degree on the design and time-dependent analysis of the CFST column. More studies considering the step upload will be conducted in the future.

\section{Symbols}

\begin{tabular}{|c|c|}
\hline$E_{c}(t):$ & The elastic modulus of concrete at time $t$ \\
\hline$E_{c}^{28}:$ & The elastic modulus of concrete at 28 th day \\
\hline$E_{s}:$ & The elastic modulus of the steel tube \\
\hline & The elastic modulus of the CFST column \\
\hline & $\begin{array}{l}\text { The area of the cross section of the } \\
\text { concrete }\end{array}$ \\
\hline $\mathrm{d}_{s}:$ & The area of the cross section of the tube \\
\hline & $\begin{array}{l}\text { Ratio between cross areas of steel and } \\
\text { concrete }\end{array}$ \\
\hline ?: & $\begin{array}{l}\text { The ratio between the elastic modulus of } \\
\text { the steel and the concrete at } t \text { time }\end{array}$ \\
\hline$N_{\mathrm{ut}}:$ & $\begin{array}{l}\text { The ultimate bearing capacity of CFST } \\
\text { column at } t \text { time (days) }\end{array}$ \\
\hline$N_{k}:$ & The bearing capacity of hollow steel tube \\
\hline$N_{r}:$ & The stability of the CFST column \\
\hline$N_{u 28}:$ & $\begin{array}{l}\text { The ultimate bearing capacity of CFST } \\
\text { column at } 28 \text { th day }\end{array}$ \\
\hline$E_{c}\left(\tau_{0}\right):$ & $\begin{array}{l}\text { The elastic modulus of concrete at loading } \\
\text { age } \tau_{0}\end{array}$ \\
\hline$\varphi\left(t, \tau_{0}\right):$ & The concrete creep coefficient \\
\hline$\xi=\alpha f_{y} / f_{c k}:$ & The hoop effect coefficient \\
\hline$D:$ & The outer diameter of the steel tube \\
\hline$T:$ & The thickness of the steel tube \\
\hline$L:$ & The length of the steel tube \\
\hline$t$. & The age of the concrete \\
\hline$e:$ & The eccentricity of the load \\
\hline$\lambda:$ & The slenderness of the column \\
\hline$\varepsilon_{c}^{c}(t):$ & $\begin{array}{l}\text { The total strain of concrete when creep is } \\
\text { with no steel confinement at age } t \text { days }\end{array}$ \\
\hline$\sigma_{c 1}^{0}\left(\tau_{0}\right):$ & $\begin{array}{l}\text { The initial stress of the concrete when } \\
\text { loaded at } \tau_{0} \text { days }\end{array}$ \\
\hline$E_{c}\left(\tau_{0}\right):$ & The elastic modulus of concrete at $\tau_{0}$ days \\
\hline$\varphi\left(t, \tau_{0}\right):$ & The creep coefficient at $t$ when loaded at $\tau_{0}$ \\
\hline$\sigma_{c 1}(t):$ & The stress of concrete at age $t$ days \\
\hline$\rho:$ & The aging coefficient of concrete \\
\hline$E_{\varphi}:$ & The age-adjusted effective modulus \\
\hline & The axial creep strain of the CFST column \\
\hline & $\begin{array}{l}\text { The axial strain of steel tube due to } \\
\text { concrete creep }\end{array}$ \\
\hline$\varepsilon_{c}^{c}:$ & $\begin{array}{l}\text { The creep strain of the concrete with no } \\
\text { steel confinement }\end{array}$ \\
\hline$\varepsilon_{c 1}^{c}:$ & $\begin{array}{l}\text { The reduced strain of the concrete due to } \\
\text { the effect of the steel tube confinement }\end{array}$ \\
\hline & The initial strain of CFST when loading \\
\hline$\varepsilon_{s 1}^{0}:$ & $\begin{array}{l}\text { The initial strain of the steel tube when } \\
\text { loaded }\end{array}$ \\
\hline$\varepsilon_{c 1}^{0}:$ & $\begin{array}{l}\text { The initial strain of the concrete when } \\
\text { loaded }\end{array}$ \\
\hline & The stress change of concrete due to creep \\
\hline$\sigma_{s 1}^{c}:$ & The stress change of steel tube due to creep \\
\hline$\varphi_{s c}\left(t, \tau_{0}\right):$ & The unity creep coefficient of CFST \\
\hline$\rho_{s c}\left(t, \tau_{0}\right):$ & The aging coefficient of CFST. \\
\hline
\end{tabular}

\section{Competing Interests}

The authors declare that they have no competing interests.

\section{References}

[1] M. D. O'Shea and R. Q. Bridge, "Design of circular thin-walled concrete filled steel tubes," Journal of Structural Engineering, vol. 126, no. 11, pp. 1295-1303, 2000.

[2] G. Giakoumelis and D. Lam, "Axial capacity of circular concrete-filled tube columns," Journal of Constructional Steel Research, vol. 60, no. 7, pp. 1049-1068, 2004.

[3] S. T. Zhong, The Concrete-Filled Steel Tubular Structures, Tsinghua University Press, 3rd edition, 2005 (Chinese).

[4] X. X. Zha, Hollow and Solid Concrete-Filled Steel Tube Columns Structure, Science Press, 2011 (Chinese).

[5] L.-H. Han, W. Li, and R. Bjorhovde, "Developments and advanced applications of concrete-filled steel tubular (CFST) structures: members," Journal of Constructional Steel Research, vol. 100, pp. 211-228, 2014.

[6] Y. F. Wang, Creep of the Concrete-Filled Steel Tubular Structures, Science Press, 2006.

[7] S. J. Tan and J. L. Qi, "Experimental investigation of the effect on strenth of concrete filled steel tubular compressive members under long-time load," Journal of Harbin Engineering University, no. 2, pp. 10-24, 1987 (Chinese).

[8] P. J. Terry, M. A. Bradford, and R. I. Gilbert, "Creep and shrinkage in concrete filled steel tubes," in Proceedings of the 6th International Symposium in Tubular Structures Melbourne, pp. 293-298, Melbourne, Australia, 1994.

[9] K. Luo, Y.-L. Pi, W. Gao, M. A. Bradford, and D. Hui, "Investigation into long-term behaviour and stability of concrete-filled steel tubular arches," Journal of Constructional Steel Research, vol. 104, pp. 127-136, 2015.

[10] L. H. Ichinose, E. Watanabe, and H. Nakai, "An experimental study on creep of concrete filled steel pipes," Journal of Constructional Steel Research, vol. 57, no. 4, pp. 453-466, 2001.

[11] W. Naguib and A. Mirmiran, "Creep modeling for concretefilled steel tubes," Journal of Constructional Steel Research, vol. 59, no. 11, pp. 1327-1344, 2003.

[12] H. Liu, Y. Wang, M. He, Y. Shi, and H. Waisman, "Strength and ductility performance of concrete-filled steel tubular columns after long-term service loading," Engineering Structures, vol. 100 , pp. 308-325, 2015.

[13] K. M. Shrestha and B. C. Chen, "Aging coefficient, creep coefficient and extrapolating aging coefficient from short term test for sealed concrete," Journal Wuhan University of Technology, Materials Science Edition, vol. 26, no. 1, pp. 154-159, 2011.

[14] S.-T. Yi, J.-K. Kim, and T.-K. Oh, "Effect of strength and age on the stress-strain curves of concrete specimens," Cement and Concrete Research, vol. 33, no. 8, pp. 1235-1244, 2003.

[15] ACI, "Prediction of creep, shrinkage, and temperature effects in concrete structures," ACI 209, ACI Special Publication, 1992.

[16] P. Shokouhi, A. Zoëga, and H. Wiggenhauser, "Nondestructive investigation of stress-induced damage in concrete," Advances in Civil Engineering, vol. 2010, Article ID 740189, 9 pages, 2010.

[17] J. Newman, "Strength and failure of concrete under shortterm, cyclic and sustained loading," in Advanced Concrete Technology-Concrete Properties, J. Newman and B. S. Choo, Eds., Elsevier, 2003. 
[18] G. T. Liu, H. Gao, and F. Q. Chen, "Microstudy on creep of concrete at early age under biaxial compression," Cement and Concrete Research, vol. 32, no. 12, pp. 1865-1870, 2002.

[19] M. M. Attard and S. Setunge, "Stress-strain relationship of confined and unconfined concrete," ACI Materials Journal, vol. 93, no. 5, pp. 432-442, 1996.

[20] I. Imran and S. J. Pantazopoulou, "Experimental study of plain concrete under triaxial stress," ACI Materials Journal, vol. 93, no. 6, pp. 589-601, 1996.

[21] A. Kwan, C. Dong, and J. Ho, "Axial and lateral stress-strain model for concrete-filled steel tubes," Journal of Constructional Steel Research, vol. 122, pp. 421-433, 2016.

[22] Z. G. Gao, D. G. Huang, and G. F. Zhao, "A method for creep stess analysis of concrete structures," China Civil Engineering Journal, vol. 34, no. 4, pp. 10-14, 2001 (Chinese). 

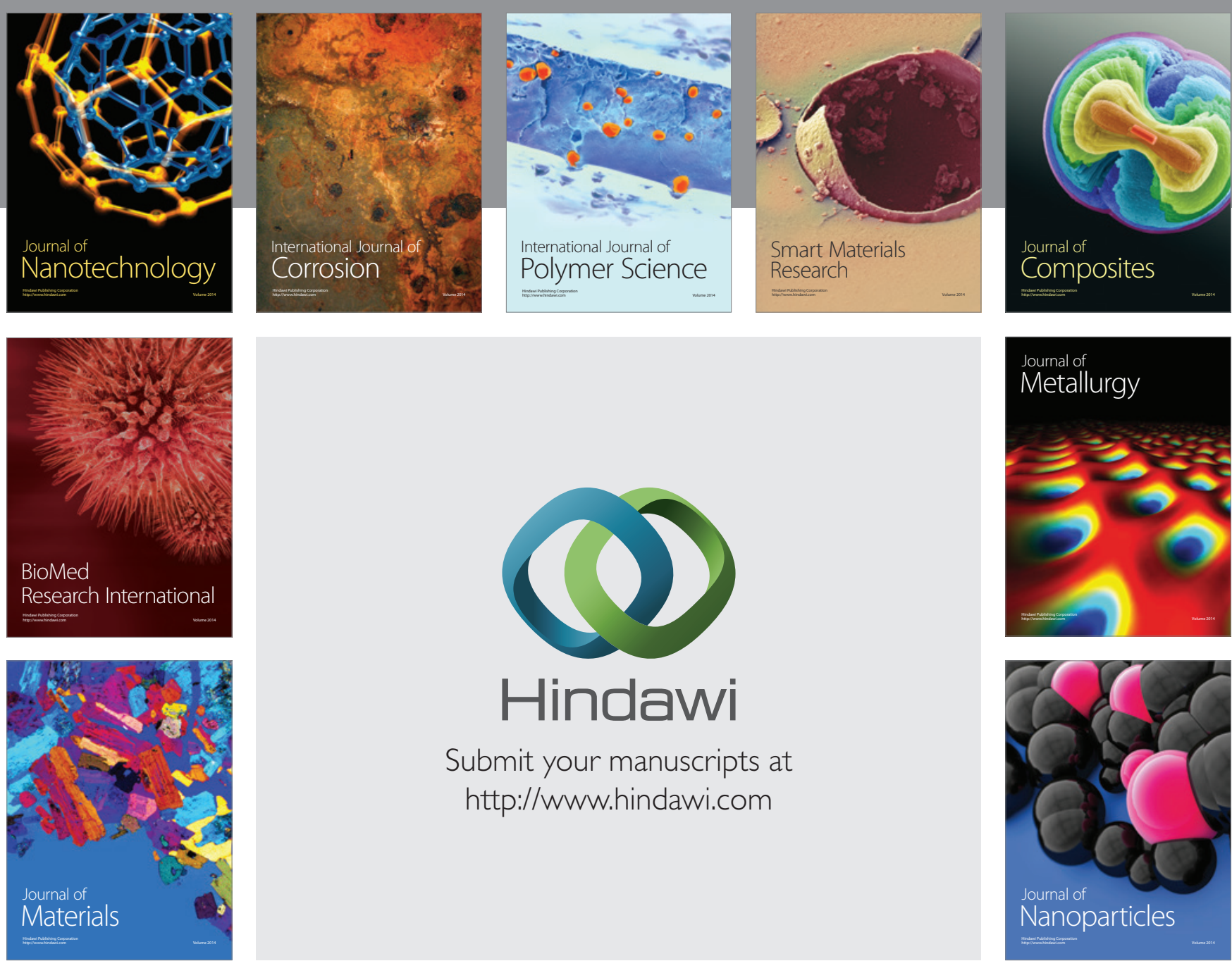

\section{Hindawi}

Submit your manuscripts at

http://www.hindawi.com

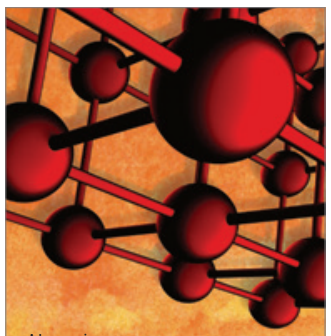

Materials Science and Engineering
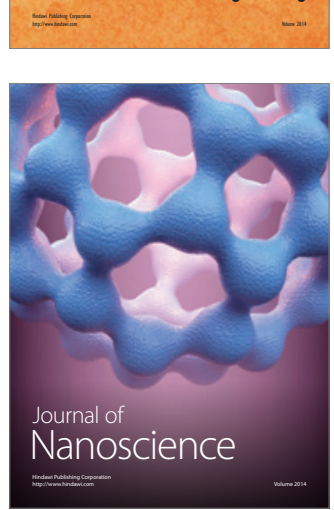
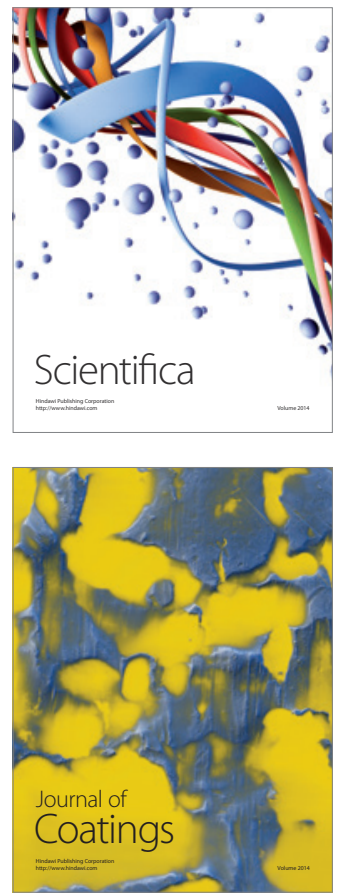
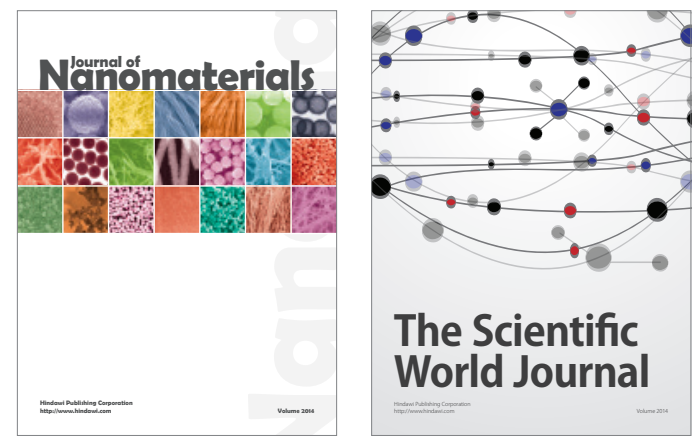

The Scientific World Journal
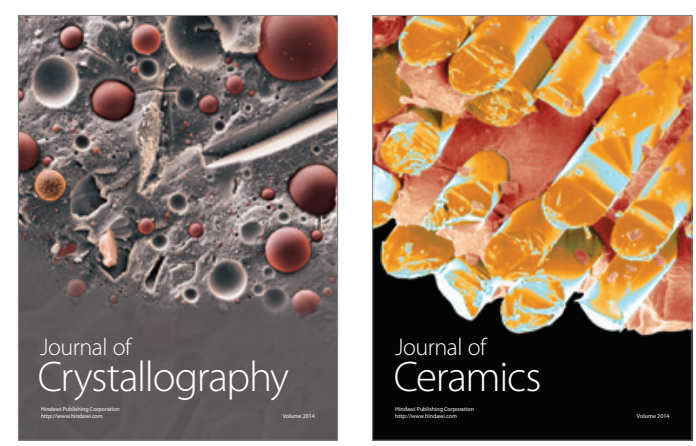
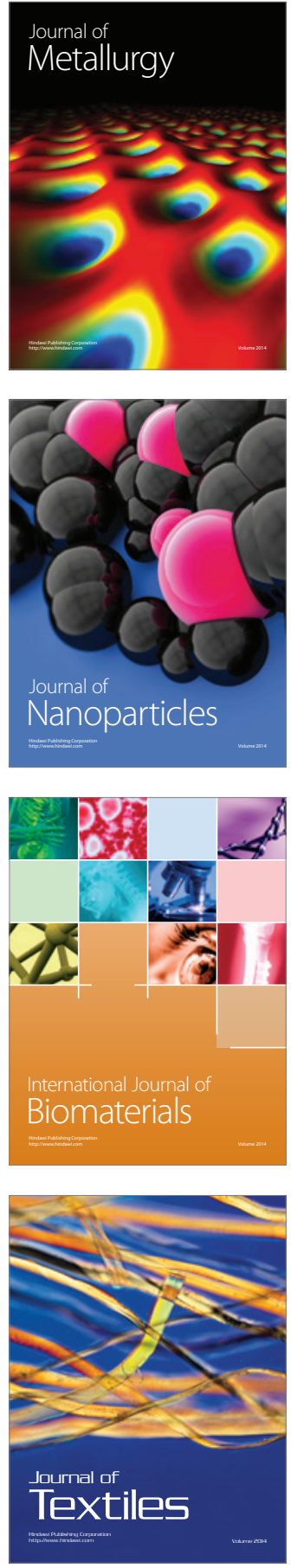